\title{
Cr(III) removal from synthetic and industrial wastewaters by using co- gasification chars of rice waste streams
}

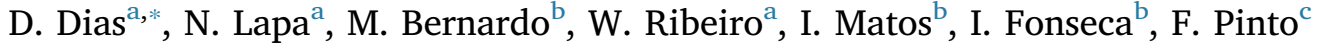 \\ ${ }^{a}$ LAQV/REQUIMTE, Departamento de Ciências e Tecnologia da Biomassa (DCTB), Faculdade de Ciências e Tecnologia (FCT), Universidade Nova de Lisboa (UNL), 2829- \\ 516 Caparica, Portugal

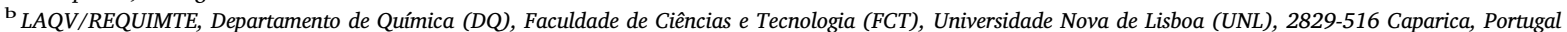 \\ ${ }^{\mathrm{c}}$ Unidade de Bioenergia (UB), Laboratório Nacional de Energia e Geologia (LNEG), Estrada do Paço do Lumiar, Ed. J, 1649-038 Lisboa, Portugal
}

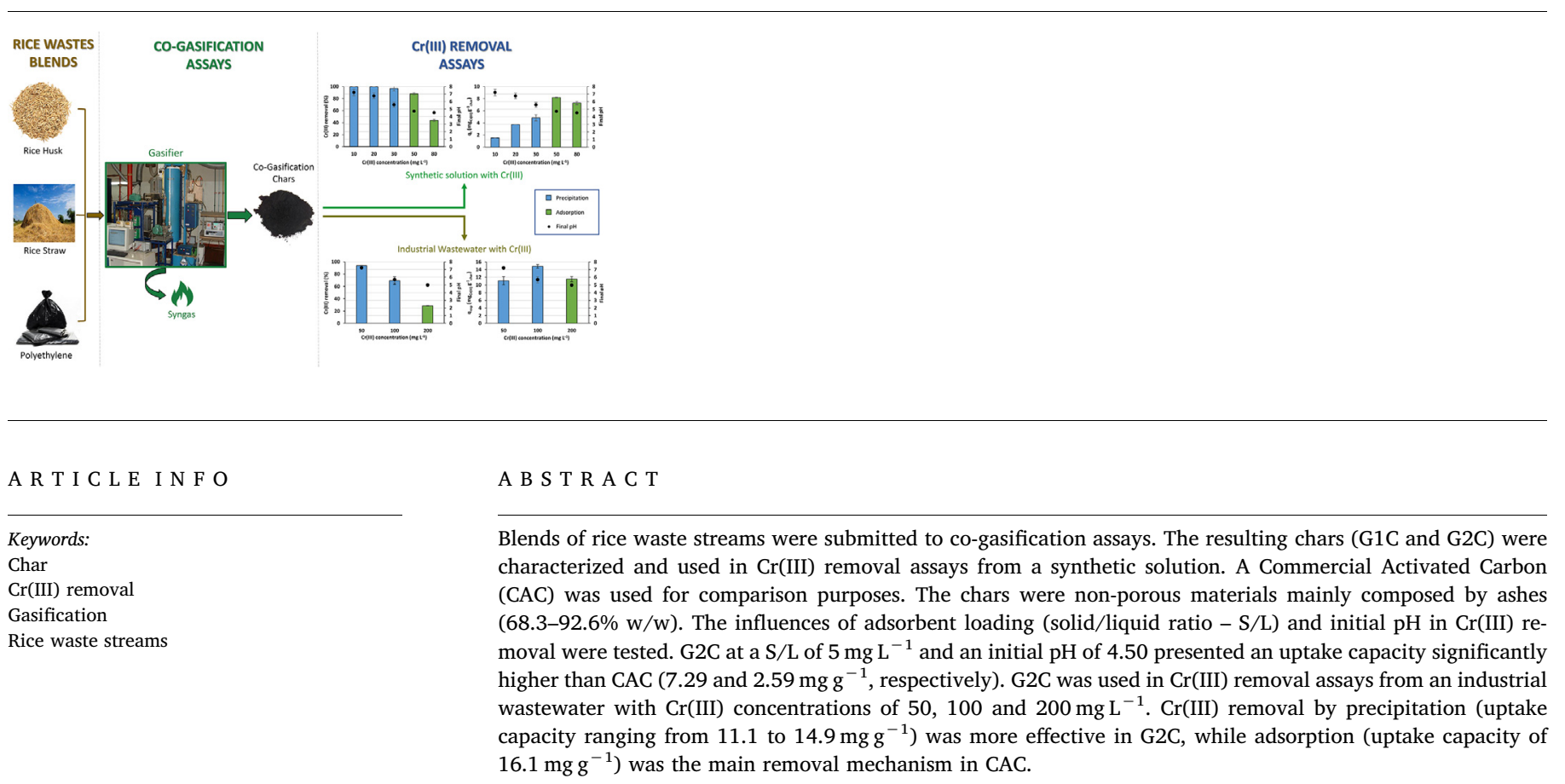

\section{Introduction}

Rice is the second most produced cereal in the world after maize. In 2017, 756.7 million tonnes of paddy rice were produced worldwide (FAO, 2017a). Portugal is the main rice consumer in Europe and the fifth larger producer after Italy, Russia, Spain and Greece, with an average annual production around 170,000 tonnes (FAO, 2017b).
The main wastes generated in rice production are rice husk (RH), rice straw (RS) and plastics; the latter are mainly composed by polyethylene (PE) from packaging of seeds and fertilizers. About $23 \% \mathrm{w} / \mathrm{w}$ of the total paddy rice is composed by RH (Prasara-A and Gheewala, 2017), and each kilogram of the harvested grain produces $1.0-1.5 \mathrm{~kg}$ of RS (Sangon et al., 2018). The current final destinations for these wastes are distinct: $\mathrm{RH}$ is used as bed material in poultry breeding, or as raw

\footnotetext{
* Corresponding author.

E-mail address: da.dias@campus.fct.unl.pt (D. Dias).
} 